\title{
Comparison of American guidelines for field triage and Polish criteria as qualification to a trauma center
}

\author{
Jacek Nowakowski ${ }^{1, A-D, F \oplus}$, Rafał Nowakowski ${ }^{1, A, C-E \oplus}{ }^{,}$Przemysław Biliński ${ }^{2, E-F \oplus}$, \\ Bogusława Nowak ${ }^{1, C-D \oplus}$, Przemysław Wojciechowski ${ }^{1, C-D \oplus}{ }^{\infty}$, Michał Dworzyński ${ }^{1, B, E} \oplus$,

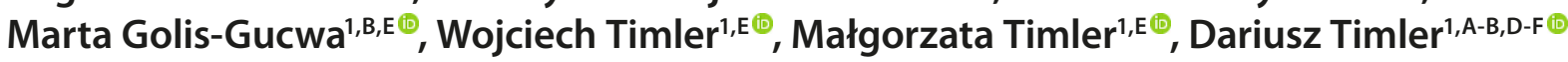 \\ ${ }^{1}$ Medical University of Lodz, Lodz, Poland \\ 2 The President Stanisław Wojciechowski State University of Applied Sciences in Kalisz, Kalisz, Poland \\ A - Research concept and design, B - Collection and/or assembly of data, C - Data analysis and interpretation, \\ $D$ - Writing the article, E-Critical revision of the article, F - Final approval of article
}

\begin{abstract}
Nowakowski J, Nowakowski R, Biliński P, Nowak B, Wojciechowski P, Dworzyński M, Golis-Gucwa M, Timler W, Timler M, Timler D. Comparison of American guidelines for field triage and Polish criteria as qualification to a trauma center. Ann Agric Environ Med. $2019 ; 26(3)$ : 479-482. doi: $10.26444 /$ aaem/100538
\end{abstract}

\begin{abstract}
Introduction. Trauma is the third cause of death among the general population in Poland, and the first in people aged 1-44 years. Trauma centers are hospitals dedicated to treating patients with multiple organ injuries, in a complex way that endeavours to ensure a lower mortality rate, shorter hospital stay and better outcomes if the patients are transferred to such a center. Worldwide, there are many models on how to treat a trauma patient, but them to be qualified for the procedure, the selection of potential patients is crucial.

Objective. The aim of the study was to compare the Polish model for qualification to a trauma center and American Guidelines for Field Triage.

Materials and method. Retrospective analysis of medical documentation recorded between 1 January 2014 - 31 December 2014 was undertaken. The study concerned trauma patients admitted to the Emergency Department of the Regional Trauma Center at the Copernicus Memorial Hospital in Łódź, Poland. Inclusion criterion was initial diagnosis 'multiple-organ injury' among patients transported by the Emergency Medical Service (EMS).

Results. In the period indicated, 3,173 patients were admitted to the Emergency Department at the Copernicus Memorial Hospital. From among them, 159 patients were included in the study. Only $13.2 \%$ of the patients fulfilled the Polish Qualification Criteria to Trauma Center in comparison to $87.4 \%$ who fulfilled the American Guidelines for Field Triage. Conclusions. Polish qualification criteria do not consider the large group of patients with severe injuries (ISS $>15)$, but indicate patients with minimal chance of survival. Polish criteria do not consider the mechanism of injury, which is a relevant predictive indicator of severe or extremely severe injuries (ISS>15). Further studies should be undertaken to improve the qualification and treatment of trauma patients in Poland.
\end{abstract}

\section{Key words}

trauma, guidelines, decision making, emergency medical services, EMS, injury, triage, ISS, multiple organ injuries, trauma center

\section{Abbreviations}

MOI - multiple organ injuries, CDC - Centers for Disease Control and Prevention, EMS - Emergency Medical Service, HEMS - Helicopter Emergency Medical Service, ISS - Injury Severity Score, AIS - abbreviates Injury Score

\section{INTRODUCTION}

Trauma is the third cause of death among the general population in Poland (6\% in 2013), and the first in people aged 1-44 years [1, 2]. Multiple-organ injuries (MOI) are particularly difficult because they demand rapid diagnostics and rapid treatment performed by a well-prepared team of specialists and emergency physicians. Trauma centers are hospitals dedicated to treating patients with multiple organ injuries in a complex way. Studies showed that trauma patients have a lower mortality rate, shorter hospital stay and better outcomes if they were transferred to a trauma center $[3,4]$. Worldwide, there are many models on how

Address for correspondence: Dariusz Timler, Medical University of Lodz, Poland e-mail: sor55@wp.pl

Received: 07.08.2018; accepted: 06.12.2018; first published: 07.01.2019 to treat trauma patients, but for all the systems one of the most crucial aspects is to establish a good identification and qualification procedure for selecting potential patients to a trauma center $[5,6]$.

\section{OBJECTIVES}

The aim of the study was to compare the Polish model of qualification to a trauma center, determinated by the Ministry of Health Regulation about Trauma Centers (entered into force on 18 June 2010) and American system Guidelines For Field Triage (CDC 2012).

General background. Between 2009 - 2010, the system of Trauma Centers was introduced in Poland which consisted 
of 14 such centers located around the whole country. There is no division of levels (stage of reference) of trauma centers, all are equipped and organized at Level I or Level II, as in the trauma centers in US. According to the Ministry of Health regulation, for patients to be qualified to a trauma center they have to fulfill at once two anatomical and two physiological criteria. Mechanism of injury is not considered (Tab. 1a) [7].

In the USA, according to Guidelines For Field Triage, to qualify a patient to a Level I or Level II trauma center, it is enough to fulfil only one criterion among anatomical, physiological, mechanism of injury criteria (Tab. 1b) [8].

\section{MATERIALS AND METHOD}

A retrospective analysis of medical documentation recorded between 1 January 2014 - 31 December 2014 was undertaken which involved trauma patients admitted to the Emergency Department of the Regional Trauma Center at the Copernicus Memorial Hospital in Lodz, Poland. Inclusion criteria were initial diagnosis 'multiple-organ injury' among patients transported by the EMS service (including HEMS, local EMS and interhospital transfers). Because no trauma registry exists in Poland, the subject of analysis was medical documentation of all patients with ICD-10 diagnosis T01-T08. Isolated injures and ambulatory cases were excluded from the analysis. Which Polish criteria for each patient was assessed and was compared to the model from Guidelines For Field Triage. To assess severity of injury, the ISS score as an independent

Table 1a. Polish Qualification Criteria to Trauma Centre.

\begin{tabular}{ll}
\hline Anatomical criteria & Physiological criteria \\
\hline $\begin{array}{ll}\text { a) Penetrating wounds of head or trunk, blast injuries with signs of involvement of internal organs, injuries around } \\
\text { head, chest and abdomen. }\end{array}$ & a) Systolic blood pressure below $80 \mathrm{~mm}$ Hg. \\
$\begin{array}{ll}\text { b) Traumatic limb amputation above the level of knee or elbow. } & \text { b) Heart rate equal to or over } 120 / \mathrm{min} . \\
\text { c) Massive crush injury of limbs. } & \text { c) Respiratory rate below } 10 \text { or over } 29 \text { per minute. } \\
\text { d) spinal cord injury } & \text { d) Glasgow Coma Scale equal or less than } 8 . \\
\text { e) Fractures with vessels or nerves injuries. } & \text { e) SpO2 equal or less than } 90 \% . \\
\text { f) Fractures of at least two proximal long bones or pelvis. } & \end{array}$ \\
\hline
\end{tabular}

Table 1b. Guidelines for field triage of injured patients - CDC, US, 2011 [8]

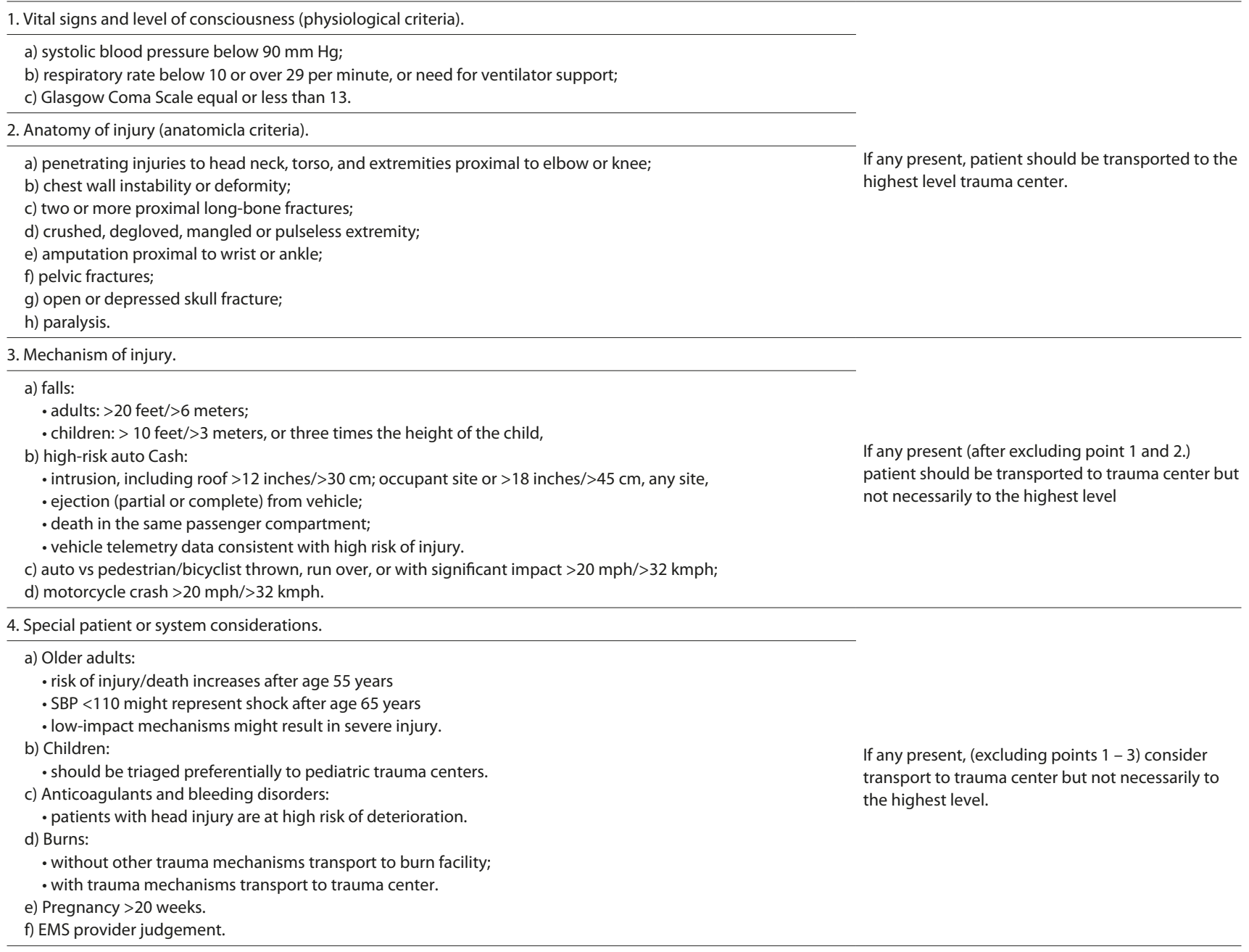


Table 2. Comparison between Polish model and American CDC Guidelines For Field Triage

\begin{tabular}{|c|c|c|c|}
\hline & Polish Ministry of Health Regulation n (\%) & American CDC Guidelines for Fieldtriage $\mathrm{n}(\%)$ & $\mathrm{p}$ \\
\hline Total number of patients & $159(100 \%)$ & & \\
\hline Number of patients fulfilling Qualification Criteria to Trauma Center & $21(13.2 \%)$ & $139 / 159(87.4 \%)$ & $<0.05$ \\
\hline Undertriage index & $96(60.4 \%)$ & $10 / 159(6.3 \%)$ & $<0.05$ \\
\hline Overtriage index & $0(0 \%)$ & $32 / 159(20.1 \%)$ & $<0.05$ \\
\hline Patients with ISS >15 & $117(73.6 \%)$ & & \\
\hline Patients with ISS $>=25$ & $69(43.4 \%)$ & & \\
\hline Patients with ISS $>=25$ fulfilling criteria & $20(29 \%)$ & $67(97.1 \%)$ & $<0.05$ \\
\hline 24-hour survival & $8(38.1 \%)$ & $16(11.5 \%)$ & $<0.05$ \\
\hline 7-day survival & $10(47.6 \%)$ & $39(28 \%)$ & $<0.05$ \\
\hline Up-to-discharge survival & 2 (9.5\%) & 93 (66.9\%) & $<0.05$ \\
\hline
\end{tabular}

indicator was calculated in each case. To calculate the ISS score, Abbreviated Injury Scale Tables (AIS) 2005, updated 2008, were used [9]. Depending on the ISS score, trauma patients were divided into three groups:

a) mild and moderate injuries (ISS $<16$ );

b) severe injuries (ISS 16-24);

c) extremely severe injuries (ISS $>24)[10,11,12]$.

All qualification criteria were correlated with actual ISS score. 24-hour-, 7-day-, up-to-discharge survival was also evaluated. Statistical analysis was performed in the program Statistica 10. Significant relevance $-p<0.05$. Approval to conduct the study was obtained from the local Ethics Committee.

\section{RESULTS}

Between 1 January 2014 - 31 December 2014, 3,173 patients were admitted to the Emergency Department at the Copernicus Memorial Hospital and from among them 159 were included to the study.

\section{DISCUSSION}

The Polish qualification criteria to trauma center do not consider the large group of patients with severe injuries (ISS $>15$ ), potentially suggesting transport to non-trauma center hospitals. The Polish criteria are too sophisticated, therefore, if the patient fulfills them, the injuries sustained are so critical that the chances of survival are minimal, independent of efforts and intensive treatment. According to ACS-COT recommendations, the over-triage rate of between $25-50 \%$ and under-triage rate of $<5 \%$ are considerated as approvable [6]. The Polish criteria do not take into consideration the mechanism of injury, which is a relevant predictive indicator of severe or extremely severe injuries (ISS>15) [8, 13]. Furthermore, Polish criteria demand the simultaneous fulfilment of four different criteria ( 2 anatomical and 2 physiological), whereas each of them individually correlates with sustaining severe injuries. In the Polish model, the probability of sustaining severe injuries is amplified, therefore, patients definitely qualified to trauma centers are very likely to die.
This study shows that to achieve an optimal over-triage rate of $25-50 \%$ and an under-triage rate of $<5 \%$. The American system based on CDC Guidelines For Field Triage should be implemented.

Additionally, other difficulties were revealed: 1) lack of a National Trauma Registry makes studies on Trauma Centers and their effectiveness extremely difficult; 2) there is no medical data standardization, and no trauma sheet exists; 3 ) documentation performed by EMS are usually incomplete for the purpose of investigating correlations between mechanism of injuries and circumstances of accidents.

Limitations. The retrospective data analysis presented in this study refers to previous years, but legislation and work organization have not been changed and remain in force to the present day. The Ministry of Health Ordinance about Qualification criteria to Trauma Center is in force and constitutes the standard of procedure in Poland.

\section{CONCLUSIONS}

It seems that the American Centers for Disease Control and Prevention (CDC) Guidelines For Field Triage should replace the Polish qualification criteria to a trauma center. Further studies should be undertaken to improve the qualification and treatment of trauma patients in Poland.

\section{REFERENCES}

1. Stańczak J, et al. Basic information about demographic development in Poland. General Statistics Departament data; 2015.

2. National Hygiene Institute. Health status of Polish Population. www. pzh.gov.pl/page/fileadmin/user_upload/statystyka/Raport_stanu_ zdrowia_2012.pdf [accessed 30.06.2016].

3. Bouzat P, Ageron FX, Brun J, Levrat A, Berthet M, Rancurel E, et al. A regional trauma system to optimize the pre-hospital triage of trauma patients. Crit Care. 2015 Mar 18; 19: 111. doi: 10.1186/s13054-0150835-7.

4. Liu T, Bai XJ. Trauma care system in China. Chin J Traumatol. 2018 Apr; 21(2): 80-83. doi: 10.1016/j.cjtee.2017.06.004. Epub 2017 Nov 4.

5. Lerner EB, Willenbring BD, Pirrallo RG, Brasel KJ, Cady CE, Colella $\mathrm{MR}$, et al. A consensus-based criterion standard for trauma center need. J Trauma Acute Care Surg. 2014 Apr; 76(4): 1157-63. doi: 10.1097/ TA.0000000000000189.

6. American College of Surgeons Committee on Trauma. Prehospital Trauma Care. In: American College of Surgeons. editor. Resources for the Optimal Care of the Injured Patient. 2006: 21区25. 
7. Dz.U. 2010 nr 118 poz. 803 - Rozporządzenie Ministra Zdrowia z dnia 18 czerwca $2010 \mathrm{r}$. w sprawie centrum urazowego.

8. Sasser SM, Hunt RC, Faul M, Sugerman D, Pearson WS, Dulski T, et al. Centres for Disease Control and Prevention (CDC). Guidelines for field triage of injured patients: recommendations of the National Expert Panel on Field Triage. 2011. MMWR Recomm Rep. 2012 Jan; 13: 61(RR-1).

9. Gennarelli TA, Wodzin E, editors. Abbreviated Injury Scale 2005 Update 2008. Barrington. IL: Association for the Advancement of Automotive Medicine; 2009.

10. Palmer CS, Gabbe BJ, Cameron PA. Defining major trauma using the 2008 Abbreviated Injury Scale. Injury. 2016 Jan; 47(1): 109-15. doi: 10.1016/j.injury.2015.07.003.
11. Smith BP, Goldberg AJ, Gaughan JP, Seamon MJ. A comparison of Injury Severity Score and New Injury Severity Score after penetrating trauma: A prospective analysis. J Trauma Acute Care Surg. 2015 Aug; 79(2): 269-74. doi: 10.1097/TA.0000000000000753.

12. Davis JW, Dirks RC, Sue LP, Kaups KL. Attempting to validate the overtriage/undertriage matrix at a Level I trauma center. J Trauma Acute Care Surg. 2017 Dec; 83(6): 1173-1178. doi: 10.1097/ TA. 0000000000001623

13. Galvagno SM Jr, Massey M, Bouzat P, Vesselinov R, Levy MJ, Millin MG, et al. Correlation Between the Revised Trauma Score and Injury Severity Score: Implications for Prehospital Trauma Triage. Prehosp Emerg Care. 2018 Aug; 23:1-8. doi: 10.1080/10903127.2018.1489019.

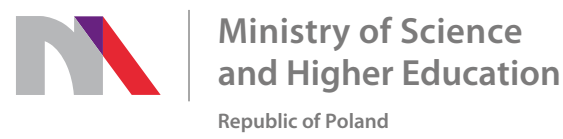

Generation of the DOI (Digital Object Identifier) - task financed under the agreement No. 618/P-DUN/2019 by the Minister of Science and Higher Education 